\title{
Com Quantos Passos Se Faz Um Caminho? - Um olhar sobre as metodolo- gias de pesquisa de/em dança do LABORARTE/UNICAMP
}

\author{
Márcia Strazzacappa ${ }^{1}$ \\ Laboratório de Estudos sobre Arte, Corpo e Educação/LABORARTE/UNICAMP \\ Mestrado Profissional em Artes em Rede Nacional/Prof-Artes/UFPB \\ $\mathrm{CNPq}$ \\ E-mail: marciastrazzacappa@gmail.com
}

\section{Resumo}

O presente ensaio almeja contribuir para as discussões relativas à produção do conhecimento em dança e em educação a partir de reflexões acerca do modus operandi do Laboratório de Estudos sobre Arte, Corpo e Educação/Laborarte, grupo de pesquisa vinculado à Faculdade de Educação da Unicamp. Para isso, apresenta e analisa algumas pesquisas de Doutorado que foram desenvolvidas sob minha orientação, descrevendo o percurso entre o projeto inicial de doutoramento e os passos dados até a tese defendida. Como recorte, foram destacadas as seguintes teses - "Gente em cena: fragmentos e memórias da dança em Goiás" de Valéria Maria Chaves Figueiredo (2007), "Uma vida em dança: movimentos e percursos de Denise Stutz" de Lilian Freitas Vilela (2010) e "De como cadeiras se movem: escrevendo meu movimento, movimentando minha escrita, uma experiência A/R/Tográfica em dança" de Scheila Maçaneiro (2013) - que trouxeram contribuições pontuais relativas às metodologias de pesquisa de/em dança e promoveram uma (auto) formação das artistas-pesquisadoras-docentes.
This essay aims to contribute to the discussion about dance and education knowledge by reflecting on the modus operandi of the Body, Art and Education Studies Laboratory/Laborarte, a research group of the School of Education at the State University of Campinas. It shows and analyses some Doctoral researches that were developed under my direction, indicating the path from the original project to the final theses. It emphasizes the following theses: "People On Stage: Fragments And Memories Of Dance In Goias" by Valeria Maria Chaves de Figueiredo (2007); "A Life In Dance: Movement And Pathways Of Denise Stutz" by Lilian Freitas Vilela (2010) and "On How Chairs Move: Writing My Movement, Moving My Writing An A/R/Tographic Experience In Dance" by Scheila Maçaneiro (2013) - that brought real contributions to dance research methodologies and promoted an (auto) formation of the artist-research-teachers. 


\section{Preâmbulo}

O pontapé inicial do presente texto surgiu após uma provocação feita pelos organizadores do II Simpósio Internacional de Formação de Educadores em Arte e Pedagogia da Universidade Mackenzie de São Paulo² ocorrido em junho de 2016 e se concretizou em 2020 após o convite para escrever um artigo para o presente dossiê. A organização do Simpósio em São Paulo havia pedido aos líderes dos grupos de pesquisa no campo da arte e da educação um vídeo de três minutos que sintetizasse a forma de se fazer pesquisa no interior de seus núcleos. A base para a produção do vídeo consistia em responder a duas perguntas pontuais: Quais as metodologias usadas pelo grupo de pesquisa? Quais referenciais teóricos usados? Naquele momento, eram múltiplos desafios: o primeiro de todos, fazer o vídeo; o segundo, falar sobre as metodologias de pesquisa de um grupo tão plural como o Laborarte; o terceiro, sintetizar todas as informações em apenas 3 minutos.

Pensei na produção do grupo, nas teses concluídas, nos projetos em andamento, nas pesquisas individuais de cada membro/a e nos projetos compartilhados financiados ou não. Afinal, o que tínhamos em comum, nós, docentes do grupo de pesquisa, em nosso trabalho investigativo? Em nossas produções? Troquei mensagens com os e as demais

1 Marcia Strazzacappa é professora aposentada da Faculdade de Educação da Unicamp e professora visitante sênior do Mestrado Profissional em Artes em Rede Nacional/Prof-Artes/UFPB. Membro do Laboratório de Estudos sobre Arte, Corpo e Educação/Laborarte. Livre Docente (Unicamp), Doutora em Arte (Universidade de Paris/França). Mestre em Educação (Unicamp). Graduada em Pedagogia (Unicamp) e em Dança (Unicamp). Bolsista de Produtividade em Pesquisa do CNPq.

2 II Simpósio Internacional de Formação de Educadores em Arte e Pedagogia organizado pelo GPAP - Grupo de Pesquisa Arte na Pedagogia da Universidade Presbiteriana Mackenzie realizado nos dias 08 a 11 de junho de 2016, no campus de Higienópolis em São Paulo. As comunicações dos/as convidados/as foram publicadas posteriormente no livro: Formação de educadores: modos de pensar e provocar encontros com a arte e a mediação cultural (2018) organizado por Mirian CELESTE, Daniel MOMOLI e Ester BONCI, São Paulo: Terracota, 2018. membros/as do grupo, dentre colegas docentes e discentes, para compartilhar ideias sobre o quê preparar para o referido simpósio, coletar imagens e, sobretudo, para pedir ajuda técnica para a produção do vídeo (lembrando que há quatro anos atrás não se estava tão familiarizado/a com as tecnologias como nos dias de hoje em que, de um dia para outro, professores e professoras tiveram de se tornar youtubers e dominar aplicativos de aula em virtude da implantação do ensino remoto frente à pandemia).

Enquanto elaborava as ideias, lembrei de um chiste que dizia o seguinte:

Um homem idoso tinha uma longa barba branca que se estendia até o meio da barriga. Certo dia, na rua, uma criança intrigada com o comprimento de sua barba, Ihe perguntou: Quando o senhor dorme, o senhor põe a barba por cima ou por baixo da coberta? Dizem que depois daquele dia, este senhor nunca mais conseguiu dormir.

Foi um pouco como o senhor barbudo da anedota acima que me senti após as perguntas do Simpósio. Ele convivia tranquilamente com sua barba e dormia sem pensar nela. Foi a partir do momento em que a criança Ihe chamou a atenção que a barba passou a fazer parte de suas preocupações. Eu também, ao longo de 20 anos à frente do grupo de pesquisa, fui orientando trabalhos de conclusão de curso, Iniciação cientifica, Mestrados, Doutorados e realizando minhas pesquisas individuais sem me ater como as fazia. Após o questionamento do Simpósio do Mackenzie, o modus operandi do grupo passou a fazer parte de minhas preocupações e, tal como o barbudo, "fiquei noites sem dormir".

Poderia seguir afirmando "brincadeiras à parte", porém, não costumo deixá-las de lado. Pelo contrário, incluo sempre em minhas palestras, conferências e em meus textos espaços para o riso. O humor, tão mal visto no mundo acadêmico (que insiste em ser sério demais), faz parte do humano e nos ajuda a compreender melhor o que somos e o que fazemos. Além disso, não posso me furtar que tenho uma personagem clownesca, Dona Clotilde, que sempre 
que possível aparece para dar suas opiniões sobre o mundo e que é, inclusive, um dos objetos de pesquisa da professora pesquisadora e artista que a encarna.

Todo este preâmbulo é para sinalizar que o texto em tela vem sendo maturado há quase cinco anos. O ensaio ganhou contorno e forma com o convite feito pela professora Josiane Franken Corrêa após a palestra "Ensino de dança e (auto)formação docente" no Projeto "Ensino Contemporâneo de Dança na Educação Básica: pedagogias possíveis” (UFPel/CNPq) em que discutimos o artigo "A educação e a fábrica de corpos" (STRAZZACAPPA, 2001) e pode ser concluído graças ao tempo expandido devido ao isolamento social em virtude da pandemia do Coronavírus.

Apresento como recorte para a análise aqui posta, pesquisas de Doutorado em dança desenvolvidas junto ao Laborarte sob minha orientação que trouxeram contribuições pontuais relativas especificamente às metodologias de pesquisa e promoveram uma (auto)formação docente. Dentro destas características, destacam-se três, quais sejam: "Gente em cena: fragmentos e memórias da dança em Goiás" de Valéria Maria Chaves Figueiredo, "Uma vida em dança: movimentos e percursos de Denise Stutz" de Lilian Freitas Vilela e "De como cadeiras se movem: escrevendo meu movimento, movimentando minha escrita, uma experiência A/R/Tográfica em dança" de Scheila Maçaneiro; defendidas respectivamente em 2007, 2010 e 2013.

\section{Fazendo pesquisas no Laborarte}

O Laboratório de Estudos sobre Arte, Corpo e Educação/Laborarte ${ }^{3}$ agrega docentes de diferentes formações e atuações como Artes Visuais, Psicologia, Música, Educação Física, Pedagogia, Dança, Teatro e Clown. Ao longo de seus mais de 25 anos de existência foram ao todo 35 títulos de Doutor e mais de 50 títulos de Mestre concedidos. Muitos doutores e doutoras aí formados encontram-se hoje como docentes de instituições públicas e privadas de ensino e, em alguns casos, foram

3 Grupo de pesquisa criado em abril de 1994 e ligado ao Programa de Pós-graduação da Faculdade de Educação. responsáveis pela implementação de novas licenciaturas no campo da dança e estão em cargos de coordenação e/ou direção, em outras palavras, o grupo vem formando líderes desde sua criação.

No Laborarte, não há uma forma única de fazer pesquisa, isto é, não há uma metodologia exclusiva nem prioritária. A pesquisa ocorre ao pesquisar, da mesma forma que "o caminho se faz ao caminhar", como já proclamavam os poetas. Nós, docentes do grupo, acreditamos na necessidade de se ouvir a questão ou o objeto de pesquisa para então definir quais os trajetos a serem trilhados (ou seja, qual a metodologia que ela demanda) para se alcançar os objetivos propostos. O mesmo se passa em relação ao referencial teórico. Não elegemos um único autor, como alguns grupos fazem por opção, nem um conjunto de autores exclusivos, mas, novamente, ouvimos as (ou ficamos atentos às) necessidades da pesquisa (objeto e metodologia), o que ela tem a dizer e, a partir daí, convidamos os interlocutores para o diálogo, isto é, os autores com os quais poderemos discutir sobre determinado assunto. Em suma:

um projeto de pesquisa não pode ser visto como uma "sentença a ser cumprida", mas deveria ser pensado como uma "carta de intenções". Nesta carta anotamos uma lista de perguntas, de desejos, de sonhos (objetivos). A partir desta lista, traçamos estratégias (metodologia), organizamo-nos no tempo (cronograma) e colocamo-nos em movimento. Convidamos alguns amigos para dialogar enquanto caminhamos (referências bibliográficas) e, à medida que avançamos, vamos encontrando e conhecendo outras pessoas (novas bibliografias). Porém, diferentemente de uma viagem em que sabemos nosso destino ou, ao menos, onde queremos chegar, numa pesquisa não temos nenhuma certeza, afinal, pesquisar é adentrar no desconhecido. Apenas ao término da viagem que saberemos onde nossa travessia nos aportou (considerações finais e/ou conclusões) ${ }^{4}$. (STRAZZACAPPA, 2019).

4 Plano individual de trabalho Professor Visitante no Prof-Artes/UFPB (Strazzacappa, 2019 - não publicado). 
Embora não tenhamos eleito um conjunto de autores nem de autoras como referencial teórico, evidenciam-se algumas inspirações poéticas como Manoel de Barros, Cora Coralina, Cecília Meirelles, Clarice Lispector, Paulo Leminski, Fernando Pessoa (e todos suas personas), para citar apenas alguns. Esses referenciais poéticos sinalizam nosso lugar de produção de conhecimento: a arte. Não somos filósofos, historiadores nem antropólogos, somos artistas. Por mais que existam aproximações entre nossas pesquisas e aquelas das áreas das ciências humanas, somos artistas que pesquisam o fazer e o ensinar Arte e, no meu caso específico, o fazer e ensinar artes cênicas, isto é, dança e teatro.

Não ter uma metodologia exclusiva para conduzir as pesquisas do grupo não significa que fazemos qualquer coisa de qualquer jeito. Pelo contrário, a ausência de uma linha condutora já reconhecida pelos pares, (órgãos de fomento, associações científicas, entre outros) demanda maior atenção por parte do/a pesquisador/a, demanda um rigor conceitual. Demanda uma explicação mais detalhada dos processos e suas escolhas, demanda, sobretudo, uma ética apurada.

Ao analisar as teses orientadas e defendidas dentro do Laborarte é possível identificar alguns caminhos recorrentes como a História Oral (Icléia THIESEN, 2005; José Carlos MEIHY, 1996), a Pesquisa-Ação (Michel THIOLLENT, 2005), a pesquisa Etnográfica (Bronislaw MALINOWSKI, 1922; Clifford GEERTZ, 1989), a pesquisa (Auto)Biográfica (António NÓVOA, 2010; Elizeu SOUZA, 2011) e, mais recentemente, a Auto-Etnografia e a Bricolagem (Sylvie FORTIN, 2009, 2014), as Imersões (Marcia STRAZZACAPPA, 2014) e a A/R/Tografia (Rita IRWIN \& DIAS, Belidson, 2013; Ricardo VIADEL, 2012 ), para citar alguns.

Pode-se igualmente identificar que essas metodologias eleitas em função dos objetos e objetivos (algumas das quais consagradas na área de ciências humanas) sofreram algumas pequenas adaptações ou profundas transformações, gerando, num primeiro momento, estranhamento e, num segundo momento, novas metodologias ainda não denominadas. Essas adaptações e transformações as quais me refiro dizem respeito praticamente a dois pontos no trato de temas que abordam a dança, o corpo e a educação.

O primeiro ponto é a maneira como os dados e/ ou os documentos de uma pesquisa são tratados. No caso da dança, especificamente, espetáculos (sejam eles ao vivo ou registrados em vídeo), ensaios e processos de criação são matéria prima de pesquisa e são tratados como documentos tanto quanto entrevistas, questionários, narrativas orais e depoimentos gravados e transcritos, ou seja, transformados em palavras sobre papel. Isso porque o gesto do corpo em movimento do artista e as sensações que ele [artista] provoca naquele que assiste [espectador/pesquisador] apesar da evidente imaterialidade, são indícios que suscitam escuta, análise e tratamento, tanto quanto os documentos escritos, concretos e palpáveis.

Imagem é texto, já afirmava Ana Angélica Albano $(2011,2018)$. Por sua vez, Ana Mae Barbosa $(1991,2018)$ defendia que a linearidade presente na leitura do texto escrito que, na sociedade ocidental, ocorre da esquerda para a direita e de cima para baixo, dirige a maneira em que os indivíduos se aproximam do conhecimento. No caso da imagem, a leitura não demanda uma ordem, nem uma direção a ser seguida. A leitura da imagem não é linear, ela é aleatória promovendo uma metodologia errante. Ao ler uma imagem o/a leitor/a faz suas escolhas e torna-se protagonista de sua ação. Ele ou ela pode iniciar a leitura por onde quiser. Pode se ater num único ponto, pode olhar cores, depois linhas, formas, pode ampliar o olhar, enfim. Segundo Barbosa, o ensino de arte foi banido das escolas durante um período justamente por contribuir para a formação de um indivíduo livre e criativo, logo, mais autônomo.

Segundo ponto se refere à postura e/ou o lócus do/a pesquisador/a. A postura não é neutra. Ela tem opções estéticas e éticas claras. Uma pesquisa nos campos da arte e da educação passa necessariamente pela experiência daquele e daquela que pesquisa. Por vezes, nas pesquisas desenvolvidas no Laborarte, interessa-nos mais a transformação do sujeito/pesquisador/a que a descoberta do ob- 
jeto/pesquisa. A pesquisa é um processo de (auto) formação do sujeito, no caso do campo da arte e da educação, um processo de (trans)formação do/a artista e do/a professor/a. Essa (trans)formação do sujeito evidencia-se mais nos processos de (auto)etnografia, $A / R /$ Tografia e da pesquisa (auto)biográfica.

A A/R/Tografia é uma metodologia de pesquisa que foi cunhada no Canadá até pouco tempo ligada exclusivamente ao campo das artes visuais. A primeira aproximação desta metodologia para a linguagem da dança ocorreu por meio da então doutoranda Scheila Maçaneiro, docente do curso de graduação em Dança da Faculdade de Artes do Paraná, como veremos mais adiante. Ao entrarmos em contato com essa metodologia que envolve, como o próprio nome já diz, uma relação estreita entre Artista, pesquisador/a (Researcher) e professor/a (Teacher), repensarmos nossas pesquisas no Laborarte, sobretudo no caso das Imersões Poético-Acadêmicas como processos de formação do Artista - Pesquisador - Docente ${ }^{5}$, ao identificar pontos de aproximação entre ambas.

Da mesma forma como selecionamos o referencial teórico a partir da escuta da pesquisa, pensamos igualmente em quem serão os/as interlocutores/ as chamados/as para as bancas, tanto do exame de qualificação quanto da defesa de tese. Sabe-se que o exame de qualificação no processo de pós-graduação costuma ser um momento crucial para o desenvolvimento do trabalho, pois outros olhos, ouvidos e corpos são chamados para analisar, avaliar e comentar a pesquisa que se apresenta naquele recorte temporal, para além dos/as próprios/as envolvidos/ as, isto é, para além dos olhos, ouvidos e corpos já viciados do/a pesquisador/a e seu/sua orientador/a. Para essa etapa tão importante do trabalho, temos buscado docentes que compartilham da (ou que sejam simpáticos à) maneira pouco convencional como pesquisamos no Laborarte (em que imagens tem o mesmo peso que texto, em que personagens

5 "Imersões Poético-Acadêmicas como processos de formação do Artista - Pesquisador - Docente" projeto com Bolsa de Produtividade em Pesquisa do CNPq (2017/2021). podem se manifestar no lugar dos/as candidatos/as, em que cenas ou performances substituem slides de PowerPoint e são legítimas formas de apresentação da pesquisa, dentre outros). O objetivo não é se fechar para conversar apenas entre os pares, como incitam alguns. Acreditamos que a universidade é o espaço do dissenso, mas que este ocorra pela discussão dos conteúdos, não da forma de expor os mesmos. $O$ desejo é termos a chance de analisar de forma verticalizada a essência da pesquisa presente no texto e na apresentação do mesmo com outros e outras pesquisadores e pesquisadoras e não ficar discutindo superficialmente formatação e regras.

A proposta não convencional não se restringe à apresentação do trabalho no momento das bancas, abrange igualmente o texto final de teses e dissertações. No Laborarte, valorizamos muito aquilo que o/a pesquisador/a tem a dizer com sua própria voz. Permitir que o/a mestrando/a ou doutorando/a consiga elaborar um pensamento e exprimi-lo num texto autoral vale muito mais que repetir, por parágrafos infindáveis, o que outros pesquisadores já disseram sobre um determinado assunto. Esperamos que os/as pós-graduandos/as sejam capazes de compreender o que leram, de se apropriar do conteúdo, de construir conhecimento e de escrever com suas próprias palavras, trazendo para o corpo do texto apenas o essencial. Dentre uma das teses defendidas no grupo, destaco o trabalho de Adilson Ledubino (2019). Sua pesquisa acerca de pacientes simulados e da metodologia MEET/Medical Education Empowered by Theater resultou numa tese escrita na forma de dramaturgia ${ }^{6}$. Embora completamente fora do padrão, o texto dramatúrgico sustentou todas as informações comumente dispostas em capítulos com introdução, metodologia, referenciais teóricos, desenvolvimento e conclusões finais.

6 "Território de Afetos: o trabalho do ator na educação médica". 2019. Tese (Doutorado) Universidade Estadual de Campinas, Faculdade de Educação, Campinas, SP. Disponível no Repositório de Teses e Dissertações SBU/ Unicamp. 
Essa maneira de se fazer pesquisa foi se construindo e consolidando ao longo dos anos como docente, como membro de bancas e como pesquisadora.

Por mais de uma vez, ao participar de bancas, presenciei situações delicadas em que os trabalhos estavam perfeitamente formatados, isto é, seguindo as normas, bem redigidos, escritos comme il fault, porém com um conteúdo pífio, para não dizer inexistente. Sim, algumas pessoas foram capazes de escrever uma dissertação sem conteúdo. De fato, ao se escrever uma dissertação, o próprio nome já diz, disserta-se sobre algum tema, não precisando, necessariamente, ser algo inédito. Já uma tese demanda a criação de uma (ou mais) hipótese(s) e sua(s) comprovação(ões), demanda a defesa de um ponto de vista, demanda questionamento e inovação.

Os trabalhos a que me referi logo acima (que não apresentavam conteúdo) eram dissertações que se assemelhavam a fichamentos de leituras com infindáveis cópias de trechos de obras já escritas, recorrentes parágrafos que se iniciavam com "segundo tal autor..." e uma lista de definições sobre conceitos já apresentados por outros autores, mas nenhuma contribuição do pesquisador ou da pesquisadora. Em minha arguição, perguntava ao/à pós-graduando/a: onde está sua voz? Devo esclarecer que considero imprescindíveis as leituras sobre o que já foi produzido sobre determinado tema, entrar em contato com o conhecimento acumulado, como também é importante estudar diversos autores, fazer fichamento das leituras, porém, acredito que essa parte do processo não precisa estar no texto final da dissertação nem da tese, deve constar como a parte submersa do iceberg, aquela que dá sustentação para a parte visível do texto. Os estudos, leituras e fichamentos são o avesso da roupa, aquilo que fica atrás do bordado, é o que se esconde na coxia do teatro.

Se fazer pesquisa é ir ao encontro do desconhecido, como afirmei anteriormente, quando se caminha por caminhos nunca antes navegados, corre-se riscos. Pesquisar é estar em risco constante. É se permitir ter mais dúvidas que certezas. Muitas vezes, finda a tese, continua-se nes- se lugar de incertezas e, ao invés de responder à pergunta inicial, mais perguntas somam-se a ela.

Dentro deste panorama do modus operandi das pesquisas realizadas no Laboratório de Estudos sobre Arte, Corpo e Educação (Laborarte), passo, a partir de agora, a apresentar especificamente três exemplos concretos de doutorados em que as pesquisadoras entraram com um projeto (uma carta de intenções) que foi transformada após a ida a campo. Ora o objeto foi alterado, ora o sujeito, ora a pergunta. Isso ocorreu pois souberam ouvir as necessidades da pesquisa e/ou sobretudo suas necessidades como pesquisadoras.

\section{Gente em cena: fragmentos e} memórias da dança em Goiás (2007) de Valéria Maria Chaves de Figueiredo.

Resumo: $O$ presente trabalho tem como objetivo apresentar a dança como arte da memória e expressa em corpos que dançam. Reconstruímos danças populares de Goiás quase que 'esquecidas', presentes apenas na memória de antigos moradores da região de Santa Cruz, cidade do Estado de Goiás. Temos como foco a perspectiva da história oral, priorizando a utilização de fontes orais, bem como, o registro de imagens. A inter-relação com a comunidade manifesta-se como condição fundamental para se apreender os modos, as histórias, os movimentos, as dramaturgias que marcam estes cotidianos e sua arte. Estas danças resistem como fragmentos, na memória de antigos moradores e sem registros oficiais. Continuam vivas na tradição da oralidade, mais particularmente, na memória do corpo, já que não são mais dançadas. Foram danças aprendidas em festas rurais locais, realizadas nos salões das fazendas da região. Entre os mutirões e pagodes, estas danças e cantos tinham intuito de agregar, coletivizar experiências, ancorando-se nas trocas e nas relações afetivas, sociais e culturais. Ao longo dos anos foram proibidas e/ou desprezadas pela modernidade capitalista. A metodologia desenvolvida envolveu o registro pela escrita, pela imagem e pela experiência vivida, formando uma rede de significações. Nossa intenção foi olhar para o corpo como um texto múltiplo e constituído de história, memória, cultura e arte. São tiranias e poesias 
inscritas no cotidiano e na dança. É a presença de uma multiplicidade de diálogos e uma dança apresentada como campo de conhecimento polissêmico. Nosso referencial teórico dialoga com diversos autores, entre eles Portelli, Olga Von Simson, Walter Benjamin, entre outros. (FIGUEIREDO, 2007).

Sua pesquisa tinha por objetivo fazer um resgate histórico, isto é, um levantamento de danças populares que eram realizadas durante algumas festividades em fazendas do interior de Goiás, mais especificamente no município de Morrinhos e Santa Cruz. Seu projeto evidenciava que se tratava de uma pesquisa etnográfica junto à comunidade de colonos habitantes das duas cidades. Ao realizar sua primeira ida a campo, a pesquisadora foi conduzida por vários moradores a casa do mais antigo morador local. Foi assim que conheceu um antigo membro das cavalhadas, um senhor de 87 anos, quase cego: Seu Alberto.

Logo no início da pesquisa, Valeria Figueiredo foi interpelada pelo seu Alberto e por outros membros da comunidade que desconfiavam de suas intenções. Eles afirmavam que ela não iria voltar. Isso porque intelectuais, universitários e jornalistas já haviam passado por lá, registrado, fotografado, entrevistado os moradores e nunca mais deram notícias. Foram várias idas e vindas da pesquisadora a campo até conseguir a confiança dos habitantes do vilarejo. Era uma imensa alegria do povoado, segundo relatos, quando viam o carro da pesquisadora despontando no horizonte.

Foi pelas memórias recontadas de Seu Alberto que as danças foram reencontradas. A pesquisa etnográfica deu lugar à pesquisa oral. Porém, não havia mais indivíduos na região com a memória das danças relatadas (Seu Alberto era o último remanescente da comunidade). Não havia tampouco outras fontes documentais, fotográficas, nem arquivos que pudessem permitir o contraponto às informações fornecidas pelo Seu Alberto e dar veracidade aos seus relatos. As poucas fotos das manifestações populares locais eram do próprio Seu Alberto e referiam-se às Cavalhadas, não às danças investigadas pela pesquisadora.
Se a pesquisadora tivesse levado a cabo a metodologia proposta inicialmente, não poderia ter concluído o trabalho. Da história oral para uma pesquisa-ação. Valéria propôs ao Seu Alberto remontar várias danças que não eram mais dançadas. A dança que estava morta na comunidade, mas presente nas memórias deste idoso de quase 90 anos, recebeu um sopro de vida, agrupou jovens e crianças da região e voltou à cena daquela pequena comunidade.

A cada mês, mais pessoas se juntavam ao redor da casa de Seu Alberto, até o momento em que a varanda de sua casa não suportava mais o número de pessoas e decidiram se encontrar no salão de festas da paróquia, gentilmente cedida pelo vigário local, para realizar os ensaios das danças, as gravações e/ou simplesmente dançar.

Se a metodologia proposta tivesse sido levada à risca, a pesquisadora teria abandonado este campo e buscado outro. A referida comunidade não teria sido revigorada com danças e cantos. E Seu Alberto teria morrido no esquecimento. $O$ que surpreendeu no trabalho é que a ida a campo permitiu àquela comunidade reviver e relembrar danças esquecidas. Mobilizou jovens e outros habitantes que antes não valorizavam essas manifestações e, seguramente, prolongou a vida de Seu Alberto.

Como, felizmente, não se tratava de uma pesquisa no campo da sociologia nem da antropologia, tratava-se de uma pesquisa artística, a arte cumpriu um de seus papéis sendo criativa e transformadora, tanto para as pessoas daquela comunidade quanto para a própria pesquisadora.

\section{Uma vida em dança: movimentos e percur- sos de Denise Stutz (2010) de Lilian Vilela.}

Resumo: Este trabalho de pesquisa acadêmica de doutorado versa sobre a história de vida artística da bailarina brasileira Denise Stutz, em seus percursos de atuação cênica, no período de 1970 até os dias atuais. A investigação está centrada nas experiências vividas pela bailarina em seus diferentes projetos poéticos, intitulados como momentos de formação, transformação e afirmação na dança. Como procedimento 
metodológico foi adotada a seleção, com recorte analítico, de suas narrativas orais por meio da transcriação (MEIHY, 2005) de seus relatos de vida trazidos em depoimentos gravados em momentos de rememorações; e de suas narrativas cênicas extraídas de seis espetáculos escolhidos como obras de referência (Maria, Maria; Folia; Não Olhe Agora; Homo politicus; 3 solos em um tempo e Justo uma imagem: cartas e processos). As narrativas cênicas foram trazidas para o texto através dos procedimentos de análise de movimento e análise de espetáculos adaptados dos estudos de LABAN (1978) e PAVIS (2003) para esta pesquisa. Assim, a fala e os movimentos cênicos de Denise Stutz vão sendo revelados no decorrer da narrativa, contracenando voz e corpo na escrita textual e imagética de uma vida em dança. Observamos que o corpo desta bailarina foi formado por diversas referências estéticas como balé clássico, dança moderna, teatro de rua, butoh e improvisação; em momentos de pertencimento a grupos, companhias de dança, coletivos artísticos, além de momentos solo. Nestas trajetórias, foi possível perceber as opções estéticas e políticas adotadas por este corpo ao dançar, como também, refletir sobre a reorganização do ambiente da dança contemporânea em relação à cena, à movimentação do corpo, às funções do bailarino e às formas de criação. Tais transformações refletem a afirmação de Denise Stutz como bailarina e de sua dança como modo de produção de sentido e expressão de vida. (VILELA, 2010).

O projeto inicial de doutorado de Vilela era pesquisar os coletivos de dança, como eram denominadas as formas de se organizar e produzir dança em grupo no início dos anos 2000. Porém, após sua ida a campo, também sempre atenta aos sinais, a pesquisa acabou focando uma única artista da dança, Denise Stutz, que participou de importantes grupos de dança no Brasil como o Grupo Corpo de Minas Gerais e Cia. Lia Rodrigues do Rio de Janeiro.

Como escrevi no prefácio de seu livro publicado a partir de sua tese:

[...] do estudo dos coletivos de/em dança e seus processos colaborativos ao estudo de um único indivíduo que dança: esta foi a trajetória percorrida por
Lilian Vilela em seu doutorado. (...) A pesquisa de Vilela demonstrou o quanto há de plural no singular do sujeito. Coletivos inscritos em um único corpo. Corpo que abriga no gesto parte da história da dança do Brasil. (STRAZZACAPPA apud VILELA, 2013, p.13).

Outro aspecto que merece destaque na pesquisa de Vilela diz respeito a sua metodologia, pautada pela História Oral em que relatos orais foram tomados como fontes documentais. A referida metodologia prevê que, do discurso oral para o escrito, os documentos passam por três fases: transcrição (registro da fala tal qual foi dita, incluindo entonações, pausas); textualização (adaptação do texto para a linguagem escrita) e transcriação (criação de um novo texto a partir da fala em que já ocorre a interpretação). Finda esta etapa, o texto final é encaminhado ao sujeito pesquisado para aprovação dos conteúdos a serem publicados. No caso de Vilela, no entanto, sua metodologia foi além.

Nesta devolutiva, foi solicitado a Denise Stutz, que realizasse a escrita manual dessa história para a composição do trabalho final. Como forma e conteúdo se entrelaçam, a (re)escrita de sua história foi incorporada ao texto, com sua grafia em forma de manuscritos.(...) Esses manuscritos (transcriações) aparecem recortados no texto e somados às narrativas cênicas. (VILELA, 2013, p. 26).

Esse processo foi considerado pela banca um ponto alto do trabalho. A descrição dos passos (metodologia) que não constava no texto original da tese foi, após a defesa, incorporado ao mesmo na versão final para que outros pesquisadores pudessem ter acesso para futuras pesquisas no campo da arte. Vide o capítulo "Aportes teóricos e procedimentos" item 3 Procedimentos Metodológicos (VILELA, 2013, pp, 23-28).

Além da metodologia de pesquisa, destaco ainda como relevante o ato da defesa de doutorado de Lilian Vilela. A artista da dança e sujeito da pesquisa, Denise Stutz, estava presente durante a banca, desde a fala de Lilian à arguição das docentes. Ao final da resposta da candidata à última arguição, na condição de presidente da sessão, passei a palavra à artis- 
ta para tecer seus comentários. Embora não seja regular, considerei uma oportunidade ímpar podermos ouvir o lado da pessoa pesquisada. Denise Stutz disse estar tocada ao ver sua vida artística tão minuciosamente estudada. Ainda brincou afirmando que "da próxima vez que um jornalista quiser me entrevistar, vou passar o contato de Lilian, pois ela conhece mais meu trabalho que eu". No dia seguinte, Denise Stutz se encontrou com pesquisadores/as do Laborarte e à noite, apresentou um espetáculo solo no teatro do SESC de Campinas/SP, aberto à comunidade.

\section{- De como cadeiras se movem: escrevendo meu} movimento, movimentando minha escrita, uma experiência $A / R /$ Tográfica em dança (2013) de Scheila Maçaneiro.

Resumo: Foi movendo cadeiras que trabaIhei nessa investigação em Dança. Por meio da metodologia de Pesquisa Educacional Baseada em Arte encontrei na prática pedagógica A/r/tografia um entrelugar educacional que proporciona aos artistas/pesquisadores/professores existirem em contigüidade, num híbrido despertar da mestiçagem texto-corpo. Proposta por professores pesquisadores da Universidade da Columbia Britânica em Vancouver, no Canadá, a A/r/ tografia é uma linguagem de fronteiras, um terreno fértil para investigações e vivências artísticas que pelo referencial metafórico do rizoma, proposto por Deleuze e Guattari, são entremeadas pela pesquisa e pelo ensino. A necessidade de autoquestionamento instiga a/r/tógrafos a uma prática viva de pesquisa, estimulando relacionamentos que se constituem por comunidades de indivíduos compromissados com um modo de ser/ estar no mundo. Pela possibilidade de um estado de entrelaçamento teoria-prática de maneira reflexiva, responsiva e relacional, a A/r/tografia provocou-me um lugar próprio dentro da pesquisa que reverberou por meio da proposição de meus modos de organização (renderings) para as práticas de ensino e supervisão de estágios da Licenciatura em Dança da Faculdade de Artes do Paraná (FAP). Um ambiente de redescobertas permeadas por negociações, em que ensinar dança se constitui como conhecimento, quando imbricado por investigações e construções artísticas. (MAÇANEIRO, 2013).
O projeto com o qual Scheila Maçaneiro se inscreveu no processo seletivo da pós-graduação da Faculdade de Educação da Unicamp visava um estudo sobre todos os egressos do curso de licenciatura em dança que atuavam na rede pública de ensino como professores concursados. Num primeiro olhar, pareceria ousado estudar TODOS os egressos de um curso com mais de 20 anos de existência, porém, durante a entrevista, a banca de seleção descobriu que este número era reduzido a quatro sujeitos. $\mathrm{A}$ pergunta que veio a seguir foi: o que haveria, então, de tão relevante nestes quatro sujeitos para se realizar tal estudo? Justamente buscar entender a relação defasada entre as licenciaturas que formam professores e o sistema de ingresso desses professores na rede pública de ensino do Estado do Paraná.

Ao longo da realização das disciplinas na pós-graduação, a então doutoranda leu um texto que iria alterar radicalmente os rumos de seus estudos. Tratava-se do capítulo $A / R /$ Tografia: uma mestiçagem metonímica de Rita Irwin (2008) presente no livro Interterritorialidade: mídias, contextos e educação organizado por Ana Mae Barbosa e Lilian Amaral. Conseguimos o contato e-mail da referida autora, docente da Universidade do Canada e responsável pela criação e divulgação de uma metodologia até então utilizada exclusivamente para o campo das artes vi-

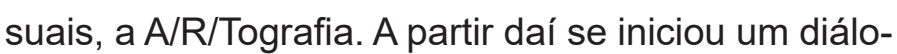
go profícuo que culminou na ida de Scheila Maçaneiro para a Universidade de British Columbia/UBC por um período de seis meses para realizar parte de seu doutoramento. Ao entrar em contato com o grupo de pesquisa e demais estudantes em doutoramento na UBC, Scheila redimensionou seu próprio tema de pesquisa e concluiu sua tese desenvolvendo um trabalho sobre a aplicação da A/R/Tografia para a dança, revendo a maneira como organizava os estágios supervisionados em dança dos/as licenciandos/as da Faculdade de Artes do Paraná, onde era docente.

No dia de sua defesa, a apresentação oral de sua tese se deu por meio de uma performance dançada, mesclando imagens projetadas e movimento corporais em cadeiras. A defesa aconteceu na sala 
ED03 no prédio Anexo da Faculdade de Educação, uma sala especialmente usada para atividades práticas corporais, com chão de madeira e sem carteiras escolares. Sua tese intitulada representou o primeiro trabalho a utilizar a A/R/Tografia no campo da dança.

Ao ver a mudança de postura antes e depois de realizar esta pesquisa, concluo que o trabaIho de Scheila Maçaneiro foi o exemplo mais evidente do quanto um processo de doutoramento pode promover a (auto)formação e transformação da artista da dança, pesquisadora e docente.

\section{Referências}

ALBANO, Ana Angélica. Conversas com jovens professores de arte. São Paulo: Loyola, 2018.

ALBANO, Ana Angélica; STRAZZACAPPA, Márcia. (Orgs.) Entrelugares do corpo e da Arte. Faculdade de Educação, Unicamp, 2011.

BARBOSA, Ana Mae. A imagem no ensino de arte. São Paulo: Perspectiva, 1991.

BARBOSA, Ana Mae. (Org). Arte-Educação: leitura no subsolo. São Paulo: Cortez, 2018.

CELESTE, Mirian; MOMOLI, Daniel; BONCI, Ester. (Orgs.). Formação de educadores: modos de pensar e provocar encontros com a arte e a mediação cultural. São Paulo: Terracota, 2018.

FIGUEIREDO, Valéria M. C. Gente em cena: fragmentos e memórias da dança em Goiás. 2007. Tese (doutorado) - Universidade Estadual de Campinas, Faculdade de Educação, Campinas, SP. 2007.

FORTIN, Sylvie. Contribuições possíveis da etnografia e da auto-etnografia para a pesquisa na prática artística. Revista Cena, Porto Alegre, UFRGS, n.7, pp.77-88, fevereiro, 2009.
FORTIN, Sylvie; GOSSELIN, Pierre. Considerações metodológicas para a pesquisa em arte no meio acadêmico. ARJ-Art Research Journal, ABRACE, ANPAP, ANPPOM e UFRN, v. 1, n. 1, jan/jun, pp.117, 2014.

GEERTZ, Clifford. A interpretação das culturas. Rio de Janeiro: LTC, 1989.

IRWIN, Rita. A/R/Tografia: uma mestiçagem metonímica. In: BARBOSA, A.M. AMARAL, L. (Orgs.) Interterritorialidade: mídias, contextos e educação. São Paulo: SENAC SP; SESC SP, 2008.

IRWIN, Rita; DIAS, Belidson. (Orgs.). Pesquisa educacional baseada em artes: A/R/Tografia. Santa Maria: EDUFSM, 2013.

LABAN, Rudolf. O domínio do Movimento. São Paulo: Summus Editorial, 1978.

LEDUBINO, Adilson. Território de Afetos: o trabalho do ator na educação médica. 2019. Tese (Doutorado em Educação). Faculdade de Educação, Unicamp, 2019.

MAÇANEIRO, Scheila. De como cadeiras se movem: escrevendo meu movimento, movimentando minha escrita, uma experiência $A / R /$ Tográfica em dança. 2013. Tese (Doutorado) - Universidade Estadual de Campinas, Faculdade de Educação, Campinas, SP. 2013.

MALINOWSKI, Bronislaw. Argonautas do pacifico ocidental. (1922) Abril Cultural, 1976. Coleção Os Pensadores, 1976.

MEIHY, José Carlos. Manual da História Oral. São Paulo: Edições Loyola, 1996.

NÓVOA, António; FINGER, M. (Orgs.). O método autobiográfico e a formação. Natal: EDUFRN, 2010, São Paulo: Paulus, 2010. 
SOUZA, Elizeu. Memória, autobiografia e diversidade. Salvador: EDUFBA, 2011.

STRAZZACAPPA, Márcia. A educação e a fábrica de corpos: a dança na escola. Cad. CEDES, Campinas, v. 21, n. 53, p. 69-83, Abr. 2001. Acesso em: 20 jan. 2021. http://dx.doi.org/10.1590/S010132622001000100005.

STRAZZACAPPA, Márcia. Educação somática e artes cênicas. Campinas: Papirus, 2012.

STRAZZACAPPA, Márcia. Imersões poéticas como processo de formação do artista-docente. Revista ARJ, v.1. n. 2, p. 96-111, 2014.

STRAZZACAPPA, Márcia. Sobre danças, andanças e mudanças: trajetórias e memórias de uma artista-docente. Campinas: Librum, 2015.

THIESEN, Icléia. Vozes do Porto: memória e história oral. São Paulo: Editora DP\&A, 2005.

THIOLLENT, Michel. Metodologia da pesquisa. São Paulo: Cortez Editora, 2005.

VIADEL, Ricardo. Quality Criteria in Visual A/r/t/ ography Photo Essays: European Perspectives After Daumier's Graphic Ideas, 2012.

VILELA, Lilian. Uma vida em dança: movimentos e percursos de Denise Stutz. 2010. Tese (Doutorado) - Universidade Estadual de Campinas, Faculdade de Educação, Campinas, SP. 2010.

VILELA, Lilian. Uma vida em dança: movimentos e percursos de Denise Stutz. São Paulo: Annablume, 2013.
Este é um artigo de acesso aberto distribuído sob os termos de uma Licença Creative Commons Atribuição 4.0 Internacional. Disponível em: <http://creativecommons.org/licenses/by/4.0>.

This is an open-access article distributed under the terms of the Creative Commons Attribution License 4.0 International. Available at: $<$ http://creativecommons.org/licenses/by/4.0>.

Ce texte en libre accès est placé sous licence Creative Commons Attribution 4.0 International. Disponible sur: <http://creativecommons.org/licenses/by/4.0>.

Recebido: 27/01/2021

Aceito: $10 / 03 / 2021$

Aprovado para publicação: 27/05/2021 